EPJ Web of Conferences 75, 03004 (2014)

DOI: $10.1051 /$ epjconf/ 20147503004

(C) Owned by the authors, published by EDP Sciences, 2014

\title{
Structural and Magnetic Properties of Fe Doped Mn-Ga Ribbons
}

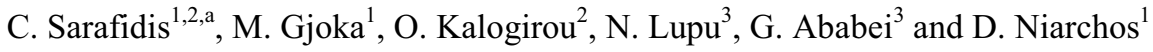 \\ ${ }^{1}$ Institute of Nanoscience \& Nanotechnology, NCSR "Demokritos", Agia Paraskevi, Greece \\ ${ }^{2}$ Third Lab. of Physics, Physics Dpt., Aristotle University of Thessaloniki, Greece \\ ${ }^{3}$ National Institute of R\&D for Technical Physics, 47 Mangeron Blvd., 700050 Iasi, Romania
}

\begin{abstract}
In the present work we study the effect on structural and magnetic properties due to the introduction of $\mathrm{Fe}$ in $\mathrm{Mn}_{2} \mathrm{Ga}$ system. $\mathrm{Mn}_{0.7-\mathrm{x}} \mathrm{Fe}_{\mathrm{x}} \mathrm{Ga}_{0.3}$ ( $x=0.1$ to 0.3 ) alloys were prepared with Ar arc-melting as base materials which were subsequently converted to ribbons using melt-spinning technique with velocity ranged from 20 to $35 \mathrm{~m} / \mathrm{s}$. Some of the materials were heat treated in a temperature range from 550 to $850{ }^{\circ} \mathrm{C}$ and for different time span, from 10 minutes to 1 hour. Alloys were studied by various characterization techniques (EDX, X-ray diffraction, magnetization versus temperature and field). The magnetic properties are improved with the increase of Fe content, Ms rises almost an order of magnitude from 0.05 per formula unit to $0.5 \mu_{\mathrm{B}}$ while low temperature coercivity reached $3.5 \mathrm{kOe}$. The temperature and duration of the thermal processing also plays a significant role. Two phases were detected, the one being stable above $973 \mathrm{~K}$. The materials present two main Curie temperatures, one above $500 \mathrm{~K}$ and one transition below room temperature.
\end{abstract}

\section{Introduction}

Decades since the discovery of $\mathrm{Nd}-\mathrm{Fe}-\mathrm{B}$ magnetic materials the search for new alloys with improved properties in permanent magnet applications is still ongoing. The last years, parameters like the cost, availability and other such related properties have gained considerable weight in the overall evaluation of a material in order to be used for applications.

Heusler alloys are an attractive class of magnetic materials since their discovery in 1903 [1] due to their property of possessing magnetic behavior while all the constituent elements are not magnetic. Plenty of new alloys were prepared and studied, with various transition metals including the magnetic ones. The discovery of many effects (half-metallicity [2], ferromagnetic shape memory effect [3], inverse magnetocaloric effect [4]) and the vast range of potential applications due to them (spintronic devices, functional materials, magnetic refrigeration) attracted a large number of researchers. These properties are easily tunable through changes in stoichiometry and processing. In addition, the complex magnetic structure and related effects, make the study of Heusler alloys useful for fundamental research in the field of magnetism in complex systems. Structural details like atomic site preference and magnetic coordination are important for the properties of Heusler alloys, governing magnetostructural phenomena or causing differences of several degrees in Curie temperatures [5-6].

\footnotetext{
$\overline{1,2, \mathrm{a}}$ Corresponding author: hsara@physics.auth.gr
}

$\mathrm{Mn}-\mathrm{Ga}$ and Fe-Mn-Ga family of materials are among the classes that have received large research attention during the last years. $\mathrm{Mn}_{3} \mathrm{Ga}$ is practically a ferrimagnet, which has also strong half-metallic character. In this material the sum of the down spins exactly cancels the sum of the up spins, and thus the term compensated half metal (CHM) was introduced [7]. It is crystallizing in a tetragonal unit cell $(\mathrm{I} 4 / \mathrm{mmm})$ which is a disordered derivative of the cubic $\mathrm{L} 2{ }_{1}$ structure but also in hexagonal and cubic variants [7-8]. It combines low magnetic moment with high Curie temperature and high spin polarization [9]. The reduction of the Mn content of the material towards $\mathrm{Mn}_{2} \mathrm{Ga}$ or with even less $\mathrm{Mn}$ content has also been studied [8, 10-12]. These alloys also present frustrated and structure/stoichiometry sensitive magnetic properties. The purpose of the present work is to check the possibility of partially replacing $\mathrm{Mn}$ for $\mathrm{Fe}$ in the $\mathrm{Mn}_{2} \mathrm{Ga}$ system and study the effects of this replacement in the magnetic properties.

\section{Experimental}

$\mathrm{Mn}_{0.7 \mathrm{x}} \mathrm{Fe}_{\mathrm{x}} \mathrm{Ga}_{0.3}(x=0.1,0.2,0.3)$ samples were prepared by arc melting in a high purity argon atmosphere. The raw materials, ingots of $\mathrm{Mn}, \mathrm{Fe}, \mathrm{Ga}$ were at least $99.9 \%$ pure. Melting was repeated three times to improve homogeneity. The as-casted bulk samples were then meltspun in a single wheel homemade apparatus. The wheel linear speed was varied in the range from 20 to $40 \mathrm{~m} / \mathrm{s}$ and the exertion differential pressure (using Ar) in most 
cases was kept constant at 0.7 bar. All the other parameters like crucible - wheel distance and crucible opening were also constant. Melt spinning, as a production technique has many advantages for the preparation of Heusler alloys, since it has a profound effect on the atomic order, which is very important for the structure and the magnetic properties of these materials [13]. Some of the samples were wrapped in tantalum foil, encapsulated in evacuated quartz tubes and annealed for various time periods ranging from 10 minutes to 1 hour at various temperatures from $923 \mathrm{~K}$ to $1123 \mathrm{~K}$. The thermal treatment was interrupted by water quenching. X-ray diffraction data of powder samples fine gridded from the ribbons were obtained using $\mathrm{CuK} \alpha$ radiation. Thermomagnetic analysis was performed by means of a Vibrating Sample Magnetometer (VSM) at a field of $0.1 \mathrm{~T}$ and $\mathrm{dT} / \mathrm{dt}$ rate of $5 \mathrm{~K} / \mathrm{s}$, values of the Curie temperature of the alloys were derived from $\mathrm{dM} / \mathrm{dT}$ versus T curves. FC-ZFC curves were recorded by using a SQUID magnetometer. Magnetization isothermal measurements at various temperatures were recorded with the VSM and SQUID instruments. Visual observation of the ribbons and chemical analysis was performed with a Scanning Electron Microscope equipped with Energy Dispersive Using X-Ray Analysis unit (EDX).

\section{Results and Discussion}

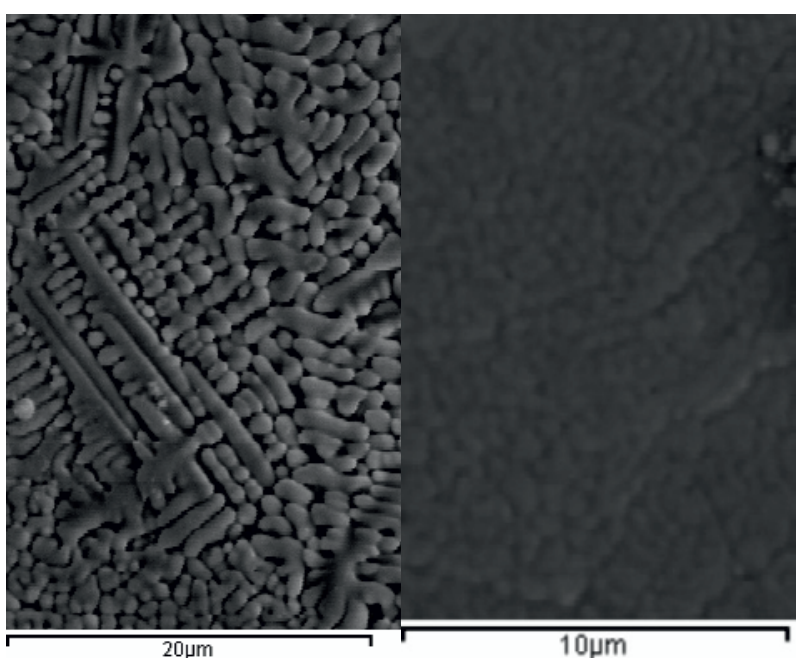

Figure 1. SEM images of $\mathrm{Mn}_{0.6} \mathrm{Fe}_{0.1} \mathrm{Ga}_{0.3}(x=0.1)$ ribbons. The left picture corresponds to a sample that was exerted with higher differential pressure from the crucible.

In Fig. 1 Scanning Electron Images of $\mathrm{Mn}_{0.7-\mathrm{x}} \mathrm{Fe}_{\mathrm{x}} \mathrm{Ga}_{0.3}$ ribbons are presented. In Table 1 the chemical stoichiometries for all alloys as analyzed with EDX micro-analysis technique are presented. As seen in Fig. 1 the typical ribbon sample appears homogenous without visible areas of different chemical composition. The development of the structure is probably columnar, with the long axis perpendicular to the ribbon surface. In samples that were prepared with higher differential pressure dendritic forming was detected, with parallel orientation relative to ribbon's surface and larger size.
Such formations have been observed also in other intermetallic systems [14]. In Table 1 the results of chemical analysis are presented. It is evident that the ribbons had constant chemical composition which was practically identical to the nominal one.

Table 1. Chemical analysis of $\mathrm{Mn}_{0.6} \mathrm{Fe}_{0.1} \mathrm{Ga}_{0.3}(x=0.1)$ ribbons.

\begin{tabular}{|c|c|c|}
\hline & Nominal & Experimental \\
\hline $\boldsymbol{x}=\mathbf{0 . 1}$ & $\mathrm{Mn}_{0.60} \mathrm{Fe}_{0.10} \mathrm{Ga}_{0.30}$ & $\mathrm{Mn}_{0.59} \mathrm{Fe}_{0.09} \mathrm{Ga}_{0.31}$ \\
\hline $\boldsymbol{x}=\mathbf{0 . 2}$ & $\mathrm{Mn}_{0.50} \mathrm{Fe}_{0.20} \mathrm{Ga}_{0.30}$ & $\mathrm{Mn}_{0.50} \mathrm{Fe}_{0.20} \mathrm{Ga}_{0.30}$ \\
\hline $\boldsymbol{x}=\mathbf{0 . 3}$ & $\mathrm{Mn}_{0.40} \mathrm{Fe}_{0.20} \mathrm{Ga}_{0.30}$ & $\mathrm{Mn}_{0.39} \mathrm{Fe}_{0.28} \mathrm{Ga}_{0.33}$ \\
\hline
\end{tabular}

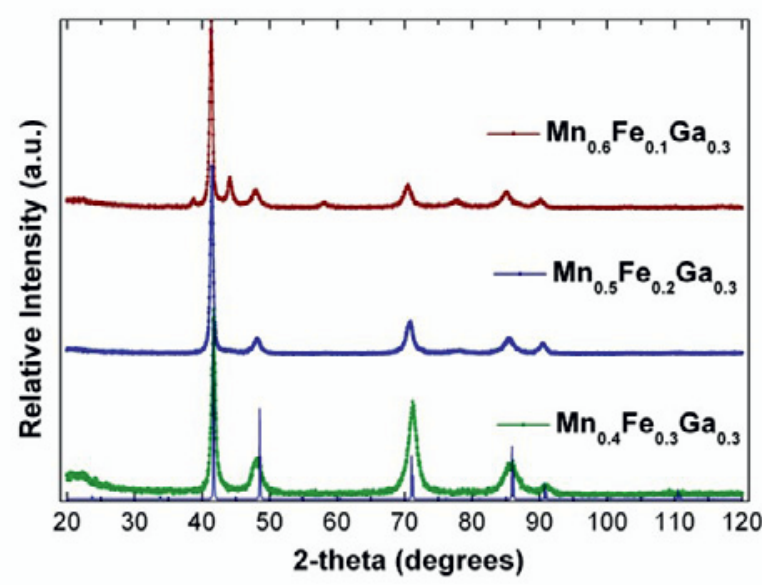

Figure 2. $\mathrm{XRD}\left(\mathrm{Cu}-\mathrm{K} \alpha\right.$ radiation) patterns of $\mathrm{Mn}_{0.7-\mathrm{x}} \mathrm{Fe}_{\mathrm{x}} \mathrm{Ga}_{0.3}(x$ $=0.1,0.2,0.3)$ as-spun ribbons. $\mathrm{L1}_{2}$-type structure simulated pattern is included in the case of $x=0.3$.

For the initial structure characterization, X-ray powder diffraction patterns were recorded with $\mathrm{Cu}-\mathrm{K} \alpha$ radiation. In Fig. 2 the diagrams for the as-spun materials are presented. It is evident that the structure of the ribbons does not strongly depend on the chemical stoichiometry. Apart from some minor peaks for the low Fe sample, which probably is a secondary phase with different structure as it is discussed later below, all main peaks are observed in the same 2-theta angle. The main peak is lowered, relative to the minor ones with increasing Fe content. The structure of the ribbons (and the main phase in the case of $x=0.1$ sample) is not fully resolved yet, but probably is a disordered variant of the $\mathrm{L1}_{2}$ cubic $\mathrm{Cu}_{3} \mathrm{Au}$-type structure. According to Kurt et al. [10] $\mathrm{Mn}_{2} \mathrm{Ga}$ crystallizes in three different structures, while Winterlik et al. [8] suggests that the $\mathrm{D}_{22}$ tetragonal one is the most prominent. Our XRD patterns present some similarity but have less peaks than expected for the tetragonal system, while the $\mathrm{L1}_{2} \mathrm{Cu}_{3} \mathrm{Au}$-type structure pattern (S.G. No 221) is more similar. 


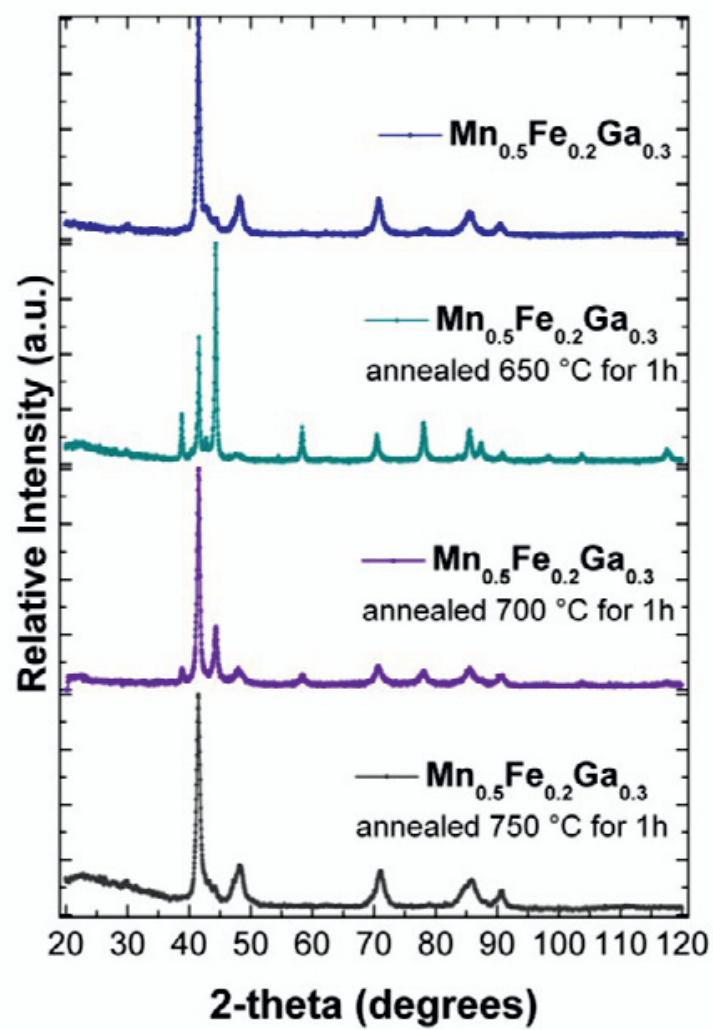

Figure 3. XRD (Cu-K $\alpha$ radiation) patterns of $\mathrm{Mn}_{0.6} \mathrm{Fe}_{0.1} \mathrm{Ga}_{0.3}(x$ $=0.2$ ) ribbons annealed at temperatures from 923 to $1023 \mathrm{~K}$.

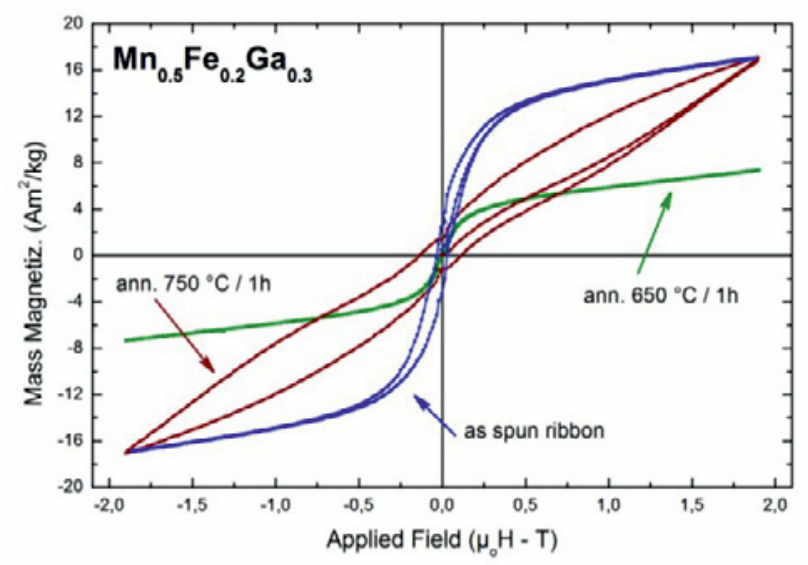

Figure 4. $\mathrm{RT}$ magnetization isotherm curves of $\mathrm{Mn}_{0.5} \mathrm{Fe}_{0.2} \mathrm{Ga}_{0.3}$ $(x=0.2)$ ribbons annealed at temperatures ranging from 923 to $1023 \mathrm{~K}$.

Thermal treatment has a clear effect on the structure of $\mathrm{Mn}_{0.7-\mathrm{x}} \mathrm{Fe}_{\mathrm{x}} \mathrm{Ga}_{0.3}$ ribbons. For relatively high annealing temperatures (1023 K and above) there is no change in the X-ray pattern, indicating that the structure is the same with the ribbons that were not thermal processed. For lower annealing temperatures, however, there is a gradual change in the structure towards the hexagonal $\mathrm{D} 0_{19}$. This phase is also present in very small amounts in the as-spun sample with the lowest $\mathrm{Fe}$ content $(x=0.1)$. It is interesting to note that in $\mathrm{Mn}_{3} \mathrm{Ga}$ and $\mathrm{Mn}_{2} \mathrm{Ga}$ the hexagonal phase is stabilized at temperatures higher than $750 \mathrm{~K}$. A more detailed study of the structural properties with Rietveld analysis of these alloys is in progress.
The magnetic properties of the materials present a degree of complexity. In Fig. 4 isothermal loops at room temperature are presented for the sample with $x=0.2$, as spun and annealed, samples at two different temperatures. The curve for the as spun sample presents a typical, low coercivity magnetic loop. The sample annealed at relatively low temperature has much lower mass magnetization and almost zero coercivity, while for the sample annealed at high temperature the loop has a very different shape, apart from the larger coercive field.

It is evident that the low temperature hexagonal phase has poorer magnetic properties at RT, probably because there is a Curie point nearby. Probably has an anti-ferro magnetic coordination like $\mathrm{Mn}_{3} \mathrm{Ga}$ isostructural [15]. The difference between the as-spun sample and the one annealed at $823 \mathrm{~K}$ is not profound, since both materials present the same crystallographic pattern. It is obvious that microstructure plays here a significant role. The shape of the loops for the high temperature annealed samples cannot exclude the possibility of a field induced transformation, from anti-ferro to ferro coordination.

Table 2. Saturation magnetization (Ms), remanent magnetization $(\mathrm{Mr})$, coercive field $\left(\mu_{0} \mathrm{H}_{\mathrm{c}}\right)$ and Curie temperature for the $\mathrm{Mn}_{0.4} \mathrm{Fe}_{0.3} \mathrm{Ga}_{0.3} \quad(\mathrm{x}=0.3)$ ribbons annealed at temperatures ranging from 923 to $1073 \mathrm{~K}$.

\begin{tabular}{|c|c|c|c|c|}
\hline Sample & $\begin{array}{c}\mathrm{Ms} \\
\left(\mathrm{Am}^{2} / \mathrm{kg}\right)\end{array}$ & $\begin{array}{c}\mathrm{Mr} \\
\left(\mathrm{Am}^{2} / \mathrm{kg}\right)\end{array}$ & $\begin{array}{c}\mu_{0} \mathrm{H}_{\mathrm{c}} \\
(\mathrm{T})\end{array}$ & $\mathrm{T}_{\mathrm{c}}(\mathrm{K})$ \\
\hline $\begin{array}{c}x=0.3, \\
\text { as spun }\end{array}$ & 51.7 & 11.0 & 0.08 & $438-581$ \\
\hline $\begin{array}{c}x=0.3 \text {, ann. } \\
923 \mathrm{~K}\end{array}$ & 39.5 & 1.1 & 0.02 & $297-401$ \\
\hline $\begin{array}{c}x=0.3 \text {, ann. } \\
973 \mathrm{~K}\end{array}$ & 34.4 & 0.1 & 0.01 & $302-408$ \\
\hline $\begin{array}{c}x=0.3 \text {, ann. } \\
1023 \mathrm{~K}\end{array}$ & 55.8 & 8.2 & 0.06 & $526-575$ \\
\hline $\begin{array}{c}x=0.3 \text {, ann. } \\
1073 \mathrm{~K}\end{array}$ & 51.3 & 12.2 & 0.30 & 574 \\
\hline
\end{tabular}

In Table 2 the magnetic properties of the $x=0.3$ alloys are summarized. $\mathrm{Mn}_{0.7-\mathrm{x}} \mathrm{Fe}_{\mathrm{x}} \mathrm{Ga}_{0.3} \quad(x=0.1,0.2)$ ribbons follow the same trend, in the case of $x=0.1$ the magnetic properties are rather poor. We report two Curie points for most of the ribbons, apart from the sample annealed at $1073 \mathrm{~K}$. As seen in Fig. 5, for the $\mathrm{x}=0.3$ samples the curves show two transitions very close to each other and obviously related. This could be attributed to the microstructure, but the possibility of a small range arrangement of magnetic moments could not be totally excluded. The best value for $\mu_{0} \mathrm{H}_{\mathrm{c}}$ obtained is higher than the $\mathrm{Mn}_{2} \mathrm{Ga}$ analogue [8]. We also observe that there is a temperature induced transition below room temperature. This is revealed in the curves of Fig. 6.

FC-ZFC for as spun samples do not show any interesting effect. However, in annealed samples, FCZFC curves do not coincide, and present a spin glass behavior. As an example, the measurement for the $x=0.3$ sample is presented in Fig. 6. A magnetic transition just 
below the RT should be a Curie point, since it is present in both FC and ZFC curves. ZFC does not reach zero at low temperatures indicating a ferri-magnetic arrangement. A transition is also observed at about 100 $\mathrm{K}$, in both $x=0.2$ and 0.3 samples, which is under investigation. The curves are similar to those reported by Winterlik et al. [8] and the small differences should be attributed to the second phase, since the samples measured were annealed at $973 \mathrm{~K}$.

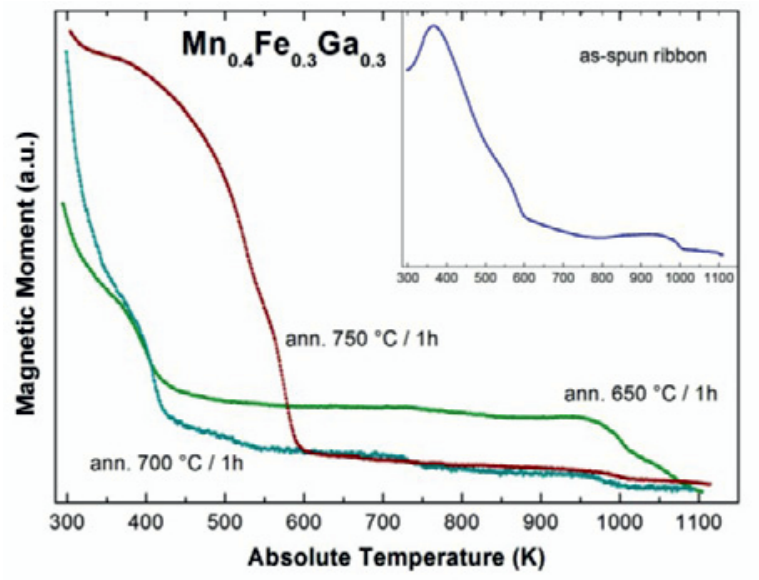

Figure 5. Magnetization versus temperature curves for $\mathrm{Mn}_{0.4} \mathrm{Fe}_{0.3} \mathrm{Ga}_{0.3} \quad(x=0.3)$ ribbons, as-spun and annealed at temperatures ranging from 923 to $1023 \mathrm{~K}$.

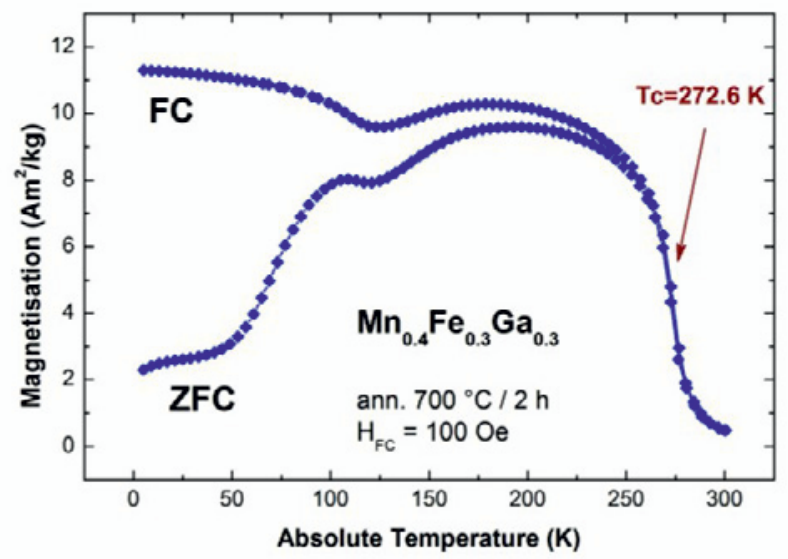

Figure 6. $\mathrm{ZFC}$ and $\mathrm{FC}$ curves for $\mathrm{Mn}_{0.4} \mathrm{Fe}_{0.3} \mathrm{Ga}_{0.3}(x=0.3)$ ribbons, annealed at $973 \mathrm{~K}$. FC curve was obtained with $100 \mathrm{Oe}$ external field.

In order to summarize our report, the $\mathrm{Mn}_{0.7-\mathrm{x}} \mathrm{Fe}_{\mathrm{x}} \mathrm{Ga}_{0.3}$ ( $x=0.1$ to 0.3 ) alloys were successfully synthesized, for the first time to our knowledge. The materials present a complex magnetic behavior which is very sensitive in both structure and microstructure and in the stoichiometry of the materials. Temperature and magnetic field induced transitions are reported.

\section{Acknowledgement}

This work is partially supported by European Commission (REFREEPERMAG project) - GA-NMP3SL-2012-280670.

\section{References}

1. F. Heusler, Deutsch. Phys. Ges. 5 (1903) 219

2. R. de Groot, F. Mueller, P. Van Engen, K.H.J. Buschow, Phys. Rev. Lett. 50 (1983) 2024

3. J. Webster, K. Ziebeck, S. Town, M. Peak, Philos. Mag. B 49 (1984) 295

4. A. Planes, L. Manosa, M. Acet, J. Phys.: Condens. Matter 21 (2009) 233201

5. S. Yu, Z. Liu, G. Liu, J. Chen, Z. Cao, G. Wu, B. Zhang, X. Zhang, Appl. Phys. Lett. 90 (2007) 242501

6. H. Luo, W. Zhu, L. Ma, G. Liu, Y. Li, X. Zhu, C. Jiang, H. Xu, G. Wu Phys. D: Appl. Phys. 42 (2009) 095001

7. S. Wurmehl, H. Kandpal, G. Fecher, C. Felser J. Phys.: Condens. Matter 18 (2006) 6171

8. J. Winterlik, B. Balke, G. Fecher, C. Felser, M. Alves, F. Bernardi, J. Morais, Phys. Rev. B 77 (2008) 054406

9. J. C. Slonczewski, J. Magn. Magn. Mater. 159 (1996) L1

10. H. Kurt, K. Rode, M. Venkatesan, P. Stamenov, J. M. D. Coey, Physical Review B 83 (2011) 020405

11. L. Zhu, D. Pan, S. Nie, J. Lu, J. Zhao, Appl. Phys. Lett. 102 (2013) 132403

12. Y. Huh, P. Kharel, V. Shah, X. Li, R. Skomski, D. Sellmyer, J. Appl. Phys. 114 (2013) 013906

13. Z. Liu, M. Zhang, Y. Cui, Y Zhou, W. Wang, G. Wu, X. Zhang, G. Xiao, Appl. Phys. Lett. 82 (2003) 424

14. C. Yang, G. Yang, Y. Lu, Y. Chen, Y. Zhou, Trans. Nonferrous Met. Soc. China 16 (2006) 39-43

15. T. Chang, C. Liang, Acta Phys. Sin. 22 (1966) 1004 